\title{
Progress in Clean-Combustion Science and Technology
}

\author{
Andreas Dreizler ${ }^{1} \cdot$ Henning Bockhorn ${ }^{2} \cdot$ Luc Vervisch $^{3} \cdot$ Amsini Sadiki $^{1}$
}

Published online: 28 October 2020

(C) The Author(s) 2020

\section{Preface}

This Special Issue reflects the scientific progress presented at the International Workshop on Clean Combustion: Principles and Applications held in Darmstadt, Germany, in the period September 25th-26th, 2019. The Workshop was organized within the framework of two Collaborative Research Centres, namely (1) Turbulent, Chemically Reactive, Multiphase Flows Near Walls, and (2) Oxy-flame-Development of Methods and Models to Describe Solid Fuel Reactions within an Oxy-fuel Atmosphere, both funded by the German Research Foundation (Deutsche Forschungsgemeinschaft-DFG). The workshop was held in honor of Professor Johannes Janicka, on the occasion of his retirement, to celebrate his seminal contributions to turbulent combustion science and modelling.

Topics in this Special Issue cover combustion principles and applications, as well as progress in theoretical, numerical and experimental techniques for describing and designing green-energy technologies. Also addressed are developments and advances in various engineering and process applications, exposing new research challenges. The topics include reciprocating internal combustion engines, gas turbines, exhaust-gas after-treatment systems in automotive technology, oxy-fuel and-solid fuel combustion. Within these areas of application, a wide range of physicochemical mechanisms and processes are investigated, among them: chemically reacting solid particles, spray-wall interaction, liquid film evaporation and deposition, film growth, flame-wall interaction and surface reactions including their coupling with chemically reacting flows.

The workshop offered an opportunity for researchers and interested practitioners to expose the state-of-the-art, discuss new challenges and developments, exchange innovative ideas, deepen existing collaborations and initiate new cooperation activities.

The editors named below hope that this Special Issue will be judged to be a milestone in the ongoing quest for "greening" combustion systems by reducing harmful emissions as close to zero as possible.

Andreas Dreizler, Technical University of Darmstadt, Germany

Henning Bockhorn, Karlsruhe Institute of Technology, Germany

Andreas Dreizler

dreizler@rsm.tu-darmstadt.de

1 Technical University of Darmstadt, Darmstadt, Germany

2 Karlsruhe Institute of Technology, Karlsruhe, Germany

3 Institut National des Sciences Appliquées de Rouen, Saint-Étienne-du-Rouvray, France 
Luc Vervisch, Institut National des Sciences Appliquées de Rouen, France Amsini Sadiki, Technical University of Darmstadt, Germany

Funding Open Access funding enabled and organized by Projekt DEAL.

Open Access This article is licensed under a Creative Commons Attribution 4.0 International License, which permits use, sharing, adaptation, distribution and reproduction in any medium or format, as long as you give appropriate credit to the original author(s) and the source, provide a link to the Creative Commons licence, and indicate if changes were made. The images or other third party material in this article are included in the article's Creative Commons licence, unless indicated otherwise in a credit line to the material. If material is not included in the article's Creative Commons licence and your intended use is not permitted by statutory regulation or exceeds the permitted use, you will need to obtain permission directly from the copyright holder. To view a copy of this licence, visit http://creativecommons.org/licenses/by/4.0/. 